TITLE:

\title{
The Abuse of Entrusted Power for Private Gain: Meaning, Nature and Theoretical Evolution
}

\author{
AUTHOR(S): \\ Pozsgai-Alvarez, Joseph
}

\section{CITATION:}

Pozsgai-Alvarez, Joseph. The Abuse of Entrusted Power for Private Gain: Meaning, Nature and Theoretical Evolution. Japan-ASEAN Transdisciplinary Studies Working Paper Series (TDWPS) 2019, 5: 1-25

ISSUE DATE:

2019-02

URL:

http://hdl.handle.net/2433/236574

RIGHT: 


\section{The Abuse of Entrusted Power for Private Gain: Meaning, Nature and Theoretical Evolution}

Joseph Pozsgai-Alvarez

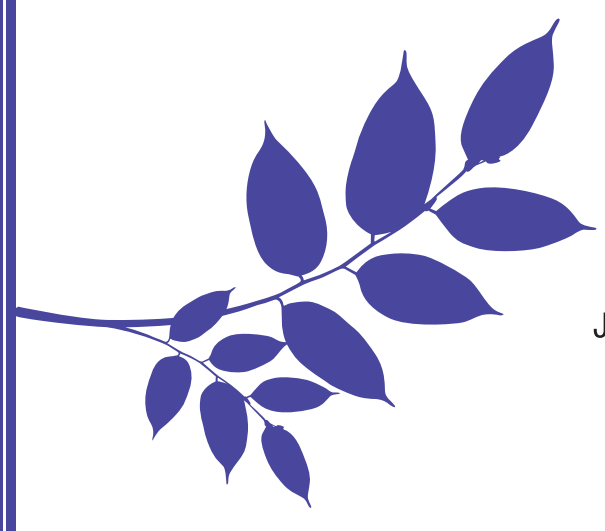

Japan-ASEAN Transdisciplinary Studies Working Paper Series No.5 February 2019 


\title{
The Abuse of Entrusted Power for Private Gain: Meaning, Nature and Theoretical Evolution
}

\author{
Joseph Pozsgai-Alvarez ${ }^{1}$ \\ ${ }^{1}$ Center for Southeast Asian Studies, Kyoto University. \\ 46 Shimoadachi-cho, Yoshida, Sakyo-ku, Kyoto 606-8501, Japan. \\ Tel: +81-75-753-9600. Email: jpozsgai@dailycorruption.info
}

\begin{abstract}
Although the study of corruption has received increasing attention over the past decades, the theoretical progress of its earlier years has been relegated to a passive comment in most quantitative studies, resulting in an underdeveloped field as a whole. To address the persistent gap in theory, this paper explicitly adopts a currently prevalent definition of corruption-i.e. the abuse of entrusted power for private gain — and explores its meaning, nature, and theoretical evolution from the earliest human bands to the present era. As a result, this study finds that corruption can be understood in a more productive way by reference to the level of political agency enjoyed at any given time and place, thus allowing for a more grounded comparative research and the potential identification of social patterns which sustain corruption tolerance.
\end{abstract}


Abuse of Entrusted Power for Private Gain

\section{Introduction}

The greatest legal historian of corruption, John T. Noonan, begins his masterpiece by stating that the historical origin of bribery is reciprocity (Noonan, 1984). According to his account, corruption emerged together with the first public duty - a responsibility inherently owed and not subject to reciprocal demands. From the moment when a public action was infused with moral reason and transcended the individualistic logic of exchange, corruption appeared as the consequence of the impending broken vow, a demand for reciprocity which had become immoral. Noonan correctly identifies the first examples of corruption as those pertaining to the administration of justice, for this function was the first and most basic form of authority. Whether it was the justice offered by a king or by a judge, the earliest stories of outrage against the actions of public authorities are offered in regards to demands for legal reparation. Already by the first century B.C., Cicero is found employing the verb corrupere to mean "the evil act of paying a judge to decide unjustly in one's favor" (Noonan, 1984, 38).

The rest, as they say, is history: corruption remained the target of moralistic reform efforts until those efforts finally took hold with legal initiatives to control public corruption in the nineteenth century, and to address private corruption in the second half of the twentieth century. Today, corruption has moved away from its past rudimentary examination as an individual moral concept and is recognized as the main source of policy failure around the world. This transition required conceptual reevaluation as much as political developments over the past three centuries. However, and in contrast to the sizeable amount of attention it currently receives from scholars and practitioners, questions remain regarding even its most basic features.

The reason for the poor understanding of corruption has been scholars' tendency to bind the term to a modern liberal ideology which holds the entirety of a collectivity as both the source and ultimate beneficiary of power-the people elect the leader to create public goods, the organization hires the employee to create profits. Consequently, judgement of past organizational forms find their legal systems and social customs inherently corrupt in their traditional embrace (or at least 
tolerance) of the individual exploitation of an office of authority. Such an interpretation of nondemocratic systems infuses the concept of corruption with unnecessary normative meaning, which naturally limits the capacity to explore the true nature and evolution of corruption. Even James C. Scott's (1972) thought-provoking term 'proto-corruption' (i.e. corruption which was considered legitimate under past legal systems) fails to provide a way to engage productively in historical and intercultural comparisons, leaving corruption plainly as that which the law says it is.

Behind the implicit anachronistic moral judgement—which is pervasive in examinations of corruption-lies a conceptual issue. What is corruption? While the answer commonly creates an unnecessary debate between interchangeable terms, the actual elements included in a definition set up the boundaries of future analysis. Early definitions provided by Leff ("[c]orruption is an extra-legal institution used by individuals or groups to gain influence over the actions of the bureaucracy"; 1964,8 ), Nye ("[c]orruption is behavior which deviates from the formal duties of a public role because of private-regarding gains"; 1967, 416), Huntington (“[c]orruption is behavior of public officials which deviates from accepted norms in order to serve private ends"; 1968,59$)$, and others, all assume without hesitation that corruption belongs to a framework of differentiated public and private sectors, to the point that it is employed as shorthand for 'political' (i.e. public) corruption. This is how Scott (1972) understands it when he proposes that alternative definitions relate to public interest, public opinion, and legal norms. Naturally, the essential problem with a narrow commitment to public corruption is that it mistakes the part for the whole-after all, there is a reason why we use the label 'public' to distinguish malfeasance from other forms of corruption.

Striving to avoid yet another attempt to define corruption, this paper offers a look into the farreaching theoretical avenues that become available once ideological commitments are relinquished. This is done by developing a concrete roadmap into the nature and theoretical evolution of corruption, thus providing the basis for a much-needed and comprehensive understanding of corruption as an individual and social phenomenon.

To start such an examination of a largely misunderstood topic, Section 2 adopts a widely employed and inclusive definition of corruption - the "abuse of entrusted power for private gain," as 
offered by Transparency International—and assesses its meaning and potential to describe corruption in an encompassing yet flexible way. After its constitutive elements have been properly probed, the definition is adopted with the objective of exploring the range of theoretical possibilities which it opens. Section 3 begins the actual analytic work of considering the historical evolution of corruption. By finding common ground and developing new terms with which to handle the complexity of such a broad review, this section finds that corruption may be recognized in all stages of social development by reference to individual agency and the ways in which power is willingly transferred. After having addressed the nature of corruption and its early evolution, Section 4 argues that its current evolutionary stage may best be described by reference to the particular ethos it transgresses, and that the nature of modern administrative arrangements may explain crucial differences between integrity and compliance approaches to corruption control. Finally, Section 5 summarizes the discussion and offers potential research avenues for the future.

\section{The meaning of corruption}

To consider corruption as the 'abuse of entrusted power for private gain' might strike one as a modern construction based on the political and individualist ideals of liberalism as a value system, and of bureaucracy as a form of efficient management. After all, 'entrusted power' suggests accountability, while 'abuse' and 'gain' are terms we may understandably find in manuals of financial integrity. However, the combined effect of the three conceptual pillars on which it stands-entrusted power, private gain, and abuse-goes well beyond the limited framework of a legal interpretation of corruption. In particular, the requirement that 'abuse' (or 'misuse' in some versions) be a crucial qualifier becomes a catalyst that dissolves any previously held historical constraints. The real implication of this definition of corruption can best be demonstrated by employing a reverse engineering approach and analyzing one constitutive element at a time.

First, the notion of 'private gain' squarely puts the emphasis on the distinctive reduction of the potential beneficiaries of a decision-making process from the whole collectivity to a specific 
group or individual. In other words, the considered actions are not driven by community or group interest, but by concerns about direct or indirect self-interest. At a most inclusive level, the created division may separate the benefits accrued to an entire society from those enjoyed by only a section of it, such as a town, party, or family. At the lowest level of aggregation, private gain involves the acquisition of individual benefits rather than their distribution among the individual's organization, tribe, or kin. This major division regarding the beneficiaries of an allocation/distribution of resources makes the notion of private gain the most general element of a definition of corruption, for without it, the concept would completely lose its moral significance. Arnold Heidenheimer (2002, 141) suggests as much by pointing out that corrupt activities such as the misappropriation of funds are more ethically reprehensible when they are performed by individuals or firms, but they become less so as the number of perpetrators grows, positing an inverse relation between the collectivization of funds and moral disapproval. For this reason, corruption may be partially described as a form of privatization of collective goods, and the element of private gain allows us to defend in moral terms the actions of whistle-blower Edward Snowden-who leaked top-secret government documents in 2013 for the sake of safeguarding the citizen rights of the American people-while disapproving of former Secretary of Defense Donald Rumsfeld and his financial links to the procurement of antiviral medication Tamiflu during the avian influenza outbreak of 2005.

Second, 'entrusted power' crucially serves to differentiate actions which can be characterized only as betrayal from those events which reflect individual autonomy and discretion but which occur outside pre-existing relationships. In its handling of resources or privileged access purposefully received and not generated by the agent itself, corruption thus represents a treacherous act against the terms of an implicit or explicit contract between parties. Under this contract, whatever its clauses may be, one party bestows power upon another without actually surrendering it; the first party merely grants it for the purpose of performing tasks or achieving goals in a more efficient or effective way. Therefore, whatever actions may follow can properly be labeled corruption only if they are performed by virtue of, or are facilitated by, a previous transfer of power 
from its legitimate source to the recipient. We may easily see the distinction when considering the terms larceny and embezzlement, only the second of which can properly be considered an act of corruption. In the first instance, the protagonist of the action and the victim need not be related in any shape or form prior to the incident; the offender uses his or her own resources to bring about the unwilling transfer of valuables from the latter to the former. On the other hand, embezzlement requires a previously established hierarchical relation through which wrongdoers gain privileged access to control or manage another party's assets, which they then transfer to themselves without being awarded consent to that end. To put it simply, larceny involves a trespass- the wrongdoer is not granted permission to control the assets in any way-while embezzlement does not- the wrongdoer is willingly awarded an initial limited control.

Moreover, for the transfer of power to work as a form of trust, it must be mutually recognized, and actors must participate willingly - i.e. both source and recipient must acknowledge (explicitly or implicitly) the nature of such a transfer as legitimate. If the recipient does not agree to the entrusted power, or if the source is forced to surrender it, no consequences could be labeled corrupt regardless of their being morally heinous. This is evident in the behavior of a conquering army, which might indulge in exploitative activities and later be called to justice for breaking international law, but not based on any anti-corruption norm.

Beyond involving transfer, entrusted power has been a source of confusion because of the vague and inconsistent operationalization of the 'power' concept. This is evident in another common definition of corruption - the abuse of public office for private gain-which avoids its explicit usage but nonetheless narrows its application to that of governmental power or official public authority. However, power is a complex concept in itself, and the way in which we employ it will naturally affect our interpretation of corruption. Consider the seemingly double standard behind corruption pertaining to public and individual actors vis-a-vis the private and organizational levels. For the public sector or the individual level, entrusted power evokes concerns about fiduciary control: power is formally and purposefully transferred, resulting in expectations that it be used with the primary objective of benefitting the original owner of power. We may call this variant a narrow 
interpretation of corruption. For the private sector or the organizational level, on the other hand, judgements of corruption are conceptually waived in their narrow form and, rather, concentrate on what may better be called a broad interpretation, conceiving of entrusted power as it is frequently discussed in the specialized literature - as a form of influence or license, closer to the typology of French and Raven (power as reward, coercion, legitimacy, reference, or expertise; 1959) than to that of Goldhamer and Shils (power as force, domination, or manipulation; Goldhamer and Shils, 1939). As Steven Lukes (2005) points out, power, influence, and other concepts are regularly used interchangeably due to a hidden core that they all share. Thus, a broad interpretation of power might allow for a potentially richer application of the term corruption, one which sees entrusted power in a wide range of relationships not limited to the public sector or even to organizational settings in general.

By themselves, entrusted power and private gain need not constitute corruption, as is evident in the contemporary transfer of public service delivery to for-profit corporations or the institutionalization of independent media in the private sector. This pattern of privatization of power over key industries has developed in parallel with the emergence of an international anti-corruption movement, which serves to legitimize it as a non-corrupt form of allocation of societal resources. Those arrangements belong to a particular stage of political and economic thought-liberalism and freemarket capitalism-whose potential for efficiency was not elaborated on in previous eras. Yet, and without considering it to be a source of efficiency, the privatization of public office had existed since antiquity - the monarchic system is based on just such a distribution of power and benefits. Why is it, then, that we now consider hereditary public office to be a form of corruption, but we draw a clear distinction in regards to private corporations engaged in public service delivery? The crucial difference lies in our understanding of corruption as a type of abuse, which becomes a catalyst to the interpretation of power (abuse as a qualifier of performance) and gain (abuse as excess in pursued benefits).

Although Gardiner $(2002,27)$ regards it impossible to define the term 'abuse,' relaying only that it means "to misuse" or "to do something improper," for Friedrich (2002) this element is the very 
core of corruption. Indeed, entrusted power for private gain can constitute corruption only under contemporary arrangements in which we include (as Transparency International and the World Bank do) the crucial element of 'abuse'. Through the catalytic effect of this third conceptual element, private gain and entrusted power interact in a way that construes corruption by reference to the relative amount of benefits an agent derives from its tasks, or the form in which these are executed.

The use of entrusted power for private gain becomes corruption when the ratio of an agent's pursued gain to that of the source of power exceeds the mutually agreed-upon level; in other words, when pursued private gain exceeds the expected or acceptable amount of rewards and rents. For example, members of parliament are legitimately assigned a salary as well as allowances, but any additional income or profit resulting from their activities may be appropriately construed as corruption. The same label would be applied to employees who use organizational resources or working hours to engage in personal activities. In both cases, the agent extracts benefits above the sanctioned amount or level, thus behaving corruptly (Philp, 2017; Rose-Ackerman, 2018).

On the other hand, the use of entrusted power for private gain becomes corruption when private gain is pursued through the employment of assigned faculties inconsistently with a mutually agreed-upon fashion - that is, by engaging in irregular activities in pursuit of otherwise appropriate goals (Jancsics, 2019). We can see this form of abuse when public servants withhold relevant information from the public to protect their positions, and when a private organization submits fraudulent financial statements. In both cases, although they continue to pursue the same objectives as their non-corrupt versions, by doing so in improper ways they effectively transition to a state which is appropriately considered corrupt.

To summarize, the necessary connections between the constitutive elements of corruption are represented in Figure 1. In describing them by reference to a principal-agent relationship, it is possible to say that power emanates from a principal (the source) and is bestowed upon representatives or agents so that they may pursue the attainment or maintenance of goods for the principal's profit, therefore making them accountable for actions performed on the principal's behalf or by virtue of 


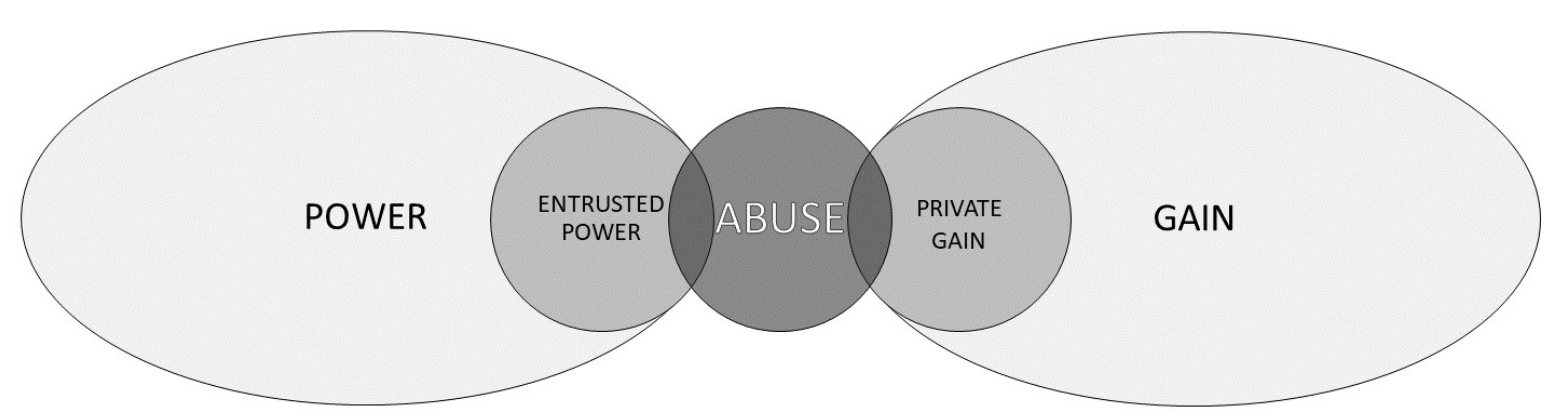

Figure 1: Corruption as the Abuse of Entrusted Power for Private Gain.

the acquired position. In return for services rendered, the principal assigns economic rewards or sources thereof (rents); however, if the agent's actions prove to have been self-serving rather than group-oriented, they are labeled corrupt, and rewards are consequently replaced by context-specific forms of punishment. This is the meaning of corruption.

\section{Nature and early evolution of corruption}

According to Howard S. Becker (1963), deviance is the label which results from the emergence of norms and their unavoidable disobedience. Thus, corruption can be said to be a deviant behavior (Friedrich, 2002, 15), as the evolution of anti-corruption enforcement over the past century clearly shows: many activities that were once considered normal business practice, or even necessary elements of the political process, are now criminally pursued. Such is the case with the bribery of foreign public officials, which in most OECD countries could be fully deducted from taxable income until the late 1990s. Noonan (1984) reports the criminalization of an increasing number of corrupt behaviors starting in the eighteenth and nineteenth centuries, allowing for a moral reflection on the issue when considering the fact that, in many respects, what is now called bribery may merely be the rejection of the principle of reciprocity in recently codified areas of human interaction. This view of corruption openly spouses the social construction of the phenomenon: the label of corruption is bound to the prevailing norms of a time and place (De Graaf, 2007; Torsello and 
Abuse of Entrusted Power for Private Gain

Venard, 2016).

However, Noonan's historical review does more than highlight the sociocultural evolution of corruption; it also describes the prevalence of corruption from the very dawn of recorded history in the form of the sale of justice. This condemnation in the ancient narrative of certain authoritative decisions as being morally reprehensible points to the very early recognition of malfeasance as a source of evil, a transgression of even the most basic ethical expectations of human collectivity. In this sense, corruption (at least in its more heinous manifestation) would appear to go beyond legal arrangements alone and to emerge as a detraction from primordial values regardless of period and culture. Such an understanding of corruption suggests a crucial role for morality that is independent of any specific set of social values. Noonan (1984) identifies the anti-corruption ideal in the administration of justice in ancient Egypt, Assyria, and Babylon. The fact that ancient corruption relates to justice is not random or coincidental: the administration of justice was historically the earliest and most basic activity associated with authority.

Considering the strong role that ethical expectations play in both origin stories described above (moral relativism versus universalism), it is clear that to understand the nature of corruption, we must address the qualities of that characteristic which is commonly considered to be its oppositeintegrity. Integrity represents the status of a value or set of values in their unimpaired condition, and it is not (contrary to common use) a moral value in itself-something evident in the hollowness of the expression 'integrity is doing the right thing.' Thus, integrity represents a state of wholeness, reflected in purposeful behavior following internalized ethical principles. In other words, it is possible to assert that integrity is a function of the congruence between individual principles and behavior; when a principle-implementation gap emerges, on the other hand, it becomes possible to assert that the individual has failed to adhere to principles due to various degrees of practical difficulty or counter-pressure (Schuman, 1972). The level of difficulty described here notoriously rises with the complexity of the situation, with equally valid principles becoming temporarily incompatible under specific circumstances.

In terms of social arrangements, early communities were not structured in a way that demanded 
much more than the observance of essential principles for human interaction. However, as institutional evolution gave birth to advanced social/economic/political functions, and as specific ethical principles emerged for the execution of new roles, the manifestation of integrity became an increasingly contentious matter. In particular, during the past two centuries, the development of meritocracy (Friedrich, 2002), government responsibility (Scott, 1972), and public welfare (Huntington, 1968) brought about a steep demand for ethical behavior tuned to progressively specialized environmental cues. The pursued congruence between organizational goals and individual behavior - as embodied in the ideals of modern administrative systems - takes the form of what will be referred to hereafter as integrity-in-office. This concept represents the ethical core of an individual's role in modern professional relations and relates to concepts such as 'public service ethos' (characterized by honesty, accountability, and the promotion of public rather than private interests; Rayner et al. 2010) and 'good corporate citizenship' (the goal of bringing organizational culture to more closely reflect the values of the larger society Gabel et al., 2009). Conversely, the absence or failure of integrity-in-office can be seen in the presence of what Michael Reisman (1979) calls 'operational codes' against 'myth systems', and its particularism-as opposed to general integrity-will account for the gap between the moral duties of individuals as members of informal social groups and those prescribed by their roles in professional organizations (Denhardt, 1994).

The counterpart of a new form of integrity is obviously a reinterpretation of corruption. Philp (2017) appropriately describes corruption as a rejection of the split between public and private spheres-a split representing the ideological core of modern bureaucracies. Mirroring the emergence of increasingly context-specific ethical expectations during the nineteenth and twentieth centuries, the historical evolution of corruption as a phenomenon of interest is marked by the shift from an exclusive focus on basic and universal forms of deviance-such as the sale of justice-to more complex and system-specific acts—-such as pork-barrel and graft. This process signaled the relabeling of previously non-deviant behavior as new forms of corruption. De Graaf $(2007,54-55)$ calls this a clashing of moral values, whereby corruption arises from two opposing sets of moral 
obligations held at once: one owed to the professional organization and the other to friends and family. This conflict is aggravated by the fact that professional and political hierarchies involve highly specialized and artificial duties; kinship, on the other hand, remains the default form of association (Fukuyama, 2011). At the heart of the problem are the duties that individuals owe to others - if a person owes another one justice but demands that they negotiate access to it, the event is properly labeled as corruption. Without duty, however, the relationship between both parties is purely transactional-one provides justice, the other provides compensation for the service. To provide a more concrete example, private security guards can be freely contracted in a legal and ethical way, whereas this is not the case with police officers, who owe service to the general public. This duty, understood as the moral obligation to provide something, is the primary source of corruption, for without it no ethical demands could be made. Consequently, the study of historic corruption may be said to be the study of duties, for the application of labels follows the recognition of context-specific duties and their ideals of integrity. However, duties are themselves a result of the way in which the individual is conceptualized and of the consequent rights which become available to members of a collectivity (Turner, 1990). This fact is evident in the way in which subjects and citizens correspond to the presence of absolute monarchies and elected governments, respectively.

Thus, a proper historical interpretation of corruption requires an understanding of the role of rights and duties in the formation of ethical expectations and their corrupt transgressions-in short, to consider the interpersonal dependencies created by the transfer of power in a group. While under modern arrangements power is mostly entrusted to pursue, in one way or another, the goals of the collectivity - that is, power is instrumental - in the past power was often transferred as a form of reward for pursuing those goals or by the forceful action of a usurper. Even within modern Western countries, there are different ways in which 'rewards' and 'trust' are interpreted, which in turn produces differing catalogues of corrupt behaviors (Philp, 2017). It is that capacity of power to be transferred in more than one way which Noonan $(1984, \mathrm{xi})$ implicitly takes to be a constituent element of a bribe, which he defines as "an inducement improperly influencing the performance of 
Abuse of Entrusted Power for Private Gain

a public function meant to be gratuitously exercised [emphasis added]." In other words, corruption implies the usufruct of what had been given only for fiduciary control; and as the specific content of the public trusteeship changes with time and culture, so does popular interpretations of corruption. Today we see the difference between entrusted power and rewarded power reflected in the publicprivate sector divide, though their distribution is much more nuanced. For example, in democratic systems the elected government is required to abide by strict recruitment regulations in filling civil service positions (i.e. merit system) but is also allowed a number of political appointee positions for discretionary selection (i.e. spoils system), thus evidencing the socially acceptable limits of public rewards vis-a-vis public duties.

Adding to these two forms, power can also be surrendered by the individual. However, while surrendered power shares with entrusted power a natural moral core-the former of opprobrium, the latter of responsibility — only the abuse of entrusted power represents corruption. As the previous section suggested, whenever power is illegitimately appropriated, it becomes impossible to speak of any duty whose betrayal may be labeled corrupt. While also morally bankrupt, the spoils of domination are never to be confused with corrupt benefits, which are applicable only to cases in which power had been willingly and purposefully transferred.

A potentially novel assessment of corruption at the historical level follows from the distinction between leadership actions that reflect duties toward the subjects/citizens (and which take the form of policy), and the actions taken in rightful enjoyment of rewards (regardless of their taking the form of salaries or taxes). Reflecting the acceptable forms of power transferred, actions labeled as corruption will also be specific to each time period and geographical area. Once it is understood that public offices can be privatized by taking them as rewards for the provision of leadership services, no difference exists between the license granted to for-profit corporations to deliver public goods in the twenty-first century and the transactional nature of many public offices in the eighteenth century (Swart, 2012). It all comes down to the way in which a group determines which forms of reward and reciprocity are acceptable and which are not. Therefore, by departing from a view of the past plagued by modern ideals, it is possible to move even further and address 
Abuse of Entrusted Power for Private Gain

the essence of that power whose transaction might or might not represent corruption-individual agency.

Agency is individuals' capacity to control their own actions beyond the demands and constraints of the environment or 'structure' (Giddens, 1984). Thus, agency and structure represent competing claims. For the present discussion, the particular dimension of structure which is of interest is the degree to which behavior may be attributed to the relationship between the individual and the rest of the group, making it the case that the highest level of sociality represents the lowest level of agency. This is what is usually referred to as 'eusociality', found mostly among insect species in which the individuals of a colony belong to a highly vertical hierarchy composed of castes of specialized labor and differentiated reproductive access (Anderson, 1984). At the other end of the spectrum are species of solitary animals which associate only for reproductive purposes. Both degrees of power transfer from the individual to the group (and all the intermediate levels found in fauna) are the results of genetic architecture and, in the case of human beings, of embedded cultural patterns (Chudek and Henrich, 2011); but inasmuch as power is not held at any of the extremes, animal groups are forced to engage in what we call politics. Politics is the struggle for control over the authoritative allocation of values in society (Easton, 1965). At its core, it depicts the struggle of the collectivity to organize itself and coordinate the activities of its members in all aspects not directly controlled by genetic demands. In other words, as long as some degree of agency is possible within a group, politics emerges as the primary means of coordination by fostering the transfer of power away from the individual. By becoming an instrument of increased sociality, politics diminishes individual agency in a temporary way, which strengthens group cohesion while keeping it adaptable. For this reason, the existence of a proper state requires the suppression of social ties based on kinship and the patrimonialism it represents, a matter evidenced early on in China through the ideology of Legalism (Fukuyama, 2011).

Historically speaking, however, while overall agency has continuously diminished due to the centralization of power by governments and its interference in private-to-private affairs (labor relations, economic transactions, childbearing, etc.), a specific type of agency which was almost 
eradicated by the first institutionalization of authority has been slowly recovering since thenpolitical agency (Crone, 1993). This concept recognizes the individual as the original source of power in society, and the struggles it inspired have only recently secured a role for individual freedom not experienced since the time of primitive bands. To differentiate those two aspects of agency, it is necessary to recognize that political agency relates solely to individual power which is transferred to the group or another agent, while general agency encompasses both transferred and non-transferred power. Crucial to our discussion is the fact that the nature of the volitional transfer of power-entrusted versus rewarded-becomes the historical origin of corruption: in early bands and tribes, any power transferred by individuals meant the recognition of 'strongmen' who used their position to settle conflicts and perform ceremonial activities. Their role was not institutionalized: decisions were not enforceable and power could be stripped away as easily as it had been voluntarily transferred (for this reason, Fried [1967] prefers to speak of 'authority' rather than 'power'). Thus, in the egalitarian societies of this kind, power could be said to have been largely rewarded rather than entrusted, thereby evidencing corruption only on those rare occasions when fairness was betrayed, and then only within the private sphere (what could be designated as 'moral corruption'). This condition of social organization was later destroyed with the institutionalization of political leadership; however, the level of entrusted power began to recover as authority became progressively codified-especially during the later stages of increasing social complexity—disengaging in the process some transactions from the concept of reciprocity and relabeling them as corrupt (Shupak, 1992; Rotaru et al.). However, rewards remained the main form of power transmission throughout this period, and wealth was legitimately owed to rulers for their role as guarantors of physical and spiritual well-being (Yoffee and Norman, 2005). Finally, the emergence of the ideologies of individualism and liberalism in the past few centuries, combined with the development of professional administrative systems, meant a new redistribution of power away from a logic of reward and towards rules of fiduciary trust. At this stage, the moral institutionalization of citizenship takes place, a process marked by broadening individual rights and limits on state power. Michael Johnston (2014) calls this event 'deep democratization,' which is 


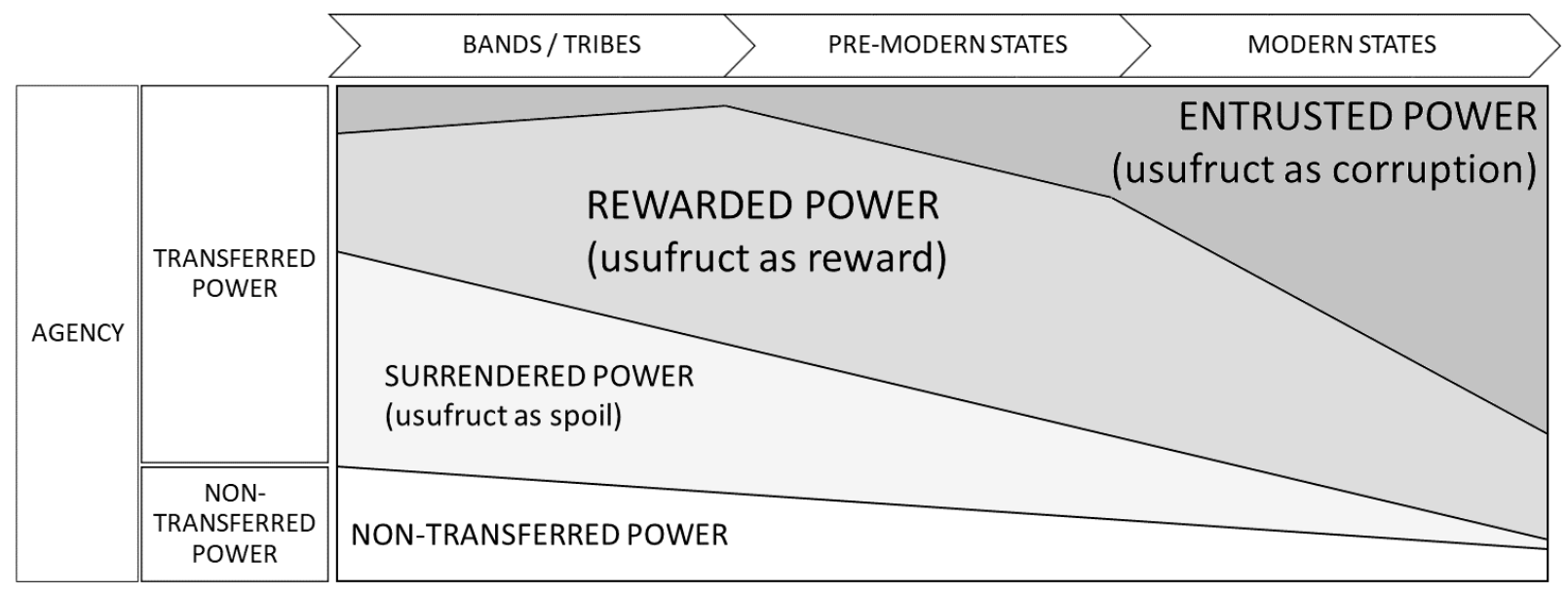

Figure 2: Evolution of Individual Agency and Corruption.

properly credited for modern efforts and progress in controlling corruption.

To provide a broad overview of this theoretical evolution, the historical applicability of the concept of corruption can be observed in Figure 2 .

\section{Late evolution of corruption}

If the transition from tribes to kingdoms and other pre-modern states (driven by the institutionalization of political authority) signaled the emergence of public corruption, the development of modern states gave way to a re-labeling of previously-accepted behaviors that would ultimately allow society to recognize corruption in the private sector as well. To better understand the significance of this process to a historical conceptualization of corruption, it becomes necessary to address the nature of corruption as it was already understood prior to the development of integrity-in-office, and to distinguish it from later forms. Therefore, as these two groups differ in respect to the increasing sociopolitical complexity of the modern state, a categorization based on the new public ethos may be suggested: primary corruption, or behavioral forms opposed to general integrity and which were already morally deviant; and secondary corruption, opposed to integrity-in-office ethics and which used to be morally acceptable. 
Abuse of Entrusted Power for Private Gain

As mentioned earlier, the complex ethical standards of modern administration foster conflict between different (but equally applicable) values, making them less clear, more open to interpretation and subversion, and more difficult to enforce. De Graaf $(2007,54)$ points out that a problem with these kinds of standards is their level of abstraction, resulting in individual and social tolerance of secondary corruption (Karklins, 2005; Pozsgai Alvarez, 2015), particularly in cases in which modern legal institutions are imposed under contexts of traditional social norms (McMullan, 1961; Johnston, 2018). By contrast, primary corruption is based on the transgression of norms which are more fundamental to social cooperation, such as access to basic goods and retributive justice. Corruption in these instances represents the rejection of the moral basis upon which a group depends for its very existence: if the adoption of mechanisms for goods sharing and altruistic punishment were crucial for the survival of early humans, the avoidance of duties and sanctions by means of corruption naturally represented a most destructive challenge. The social meaning attached to such cases of blatant corruption is still evident today in the higher standards imposed on the administration of justice and medical treatment.

If, indeed, earlier forms of corruption involved the rejection of basic social norms, while more complex forms reflect the mismatch between individual values and social rules, the arguments introduced above suggest that the former may, in fact, evidence moral pathologies, while the latter may involve more of a socialization deficit. As a consequence, the discussion of integrity and compliance which remains commonplace in the field of administrative ethics (Lewis and Gilman, 2005, Maesschalck, 2004; Arjoon, 2006) could be resolved here by acknowledging the relative weight of each of them under different conditions. The compliance approach to organizational ethics management emphasizes external controls from the top to prevent misconduct. Regular mechanisms include internal and external audits, financial controls, monitoring, investigations, limits on discretionary power, and penalties to enforce organizational standards. On the other hand, the integrity approach highlights the role of self-control from the part of employees, an appeal to values and responsible decision-making in the face of ethical dilemmas. Following its emphasis on ethical training and positive leadership, concepts which are potentially relevant to this approach 
are: moral development, or the universal sequence of stages in an individual's cognitive structures for moral judgement (Kohlberg and Hersh, 1977); moral awareness, or the individual's capacity to identify the moral content or nature of a situation (Reynolds, 2006); centrality of moral identity, or the cognitive accessibility of an individual's moral self-conception (Aquino et al., 2009); and moral disengagement, or an individual's predisposition to reinterpreting his or her own actions in a way which downplays those actions' moral content and ethical consequences (Moore, 2008). In integrating the discussion of primary and secondary corruption with the complianceintegrity dichotomy, it becomes possible to suggest that a strategy of morality maximization would (a) focus on improving the level of the target population's moral development to deal with primary corruption; (b) foster moral awareness, identity centrality, and the reduction of disengagement to curb cases of secondary corruption; and (c) adopt mechanisms of compliance to support integrity efforts. However, an efficiency maximization strategy would rather propose a behavioral intervention based on compliance for the prevention of primary corruption and integrity training initiatives to reduce secondary corruption, thus focusing on controlling the behavior of risky employees whom processes of due diligence did not filter out while still supporting the ethical development of vulnerable agents.

Clearly, a morality maximization strategy represents the ultimate goal of anti-corruption efforts. In the case of public corruption, this approach reflects the emphasis on fostering a sense of 'citizenship' which has been prevalent in both democratic theory and character education. First, it recognizes that the separation between private and public spheres which is characteristic of modern political systems requires the individual to develop a new relationship with the state-one that guarantees their political agency, thus transitioning from the role of subject to the role of citizen (Nisbet, 1974). As citizens, particularly of the liberal kind, individuals are no longer passive nonactors at the mercy of a lord or social group and confined to the private space; instead, they become fully-fledged and autonomous agents capable of participating in public life (Turner, 1990). Second, it relies on civics education that creates individuals who are sufficiently informed about the features of their society and who are capable of functioning as effective members of that society, 
Abuse of Entrusted Power for Private Gain

and on moral education that infuses them with virtues such as concern for the common good and respect for the law (Berkowitz, 2000; Sherrod et al., 2002). Although these complementary aspects of education for good citizenship regularly emphasize participation in public affairs through mechanisms associated mostly with democratic rule, at its core the approach fosters the development of individuals capable of moving beyond their private concerns and becoming more attuned to community goals and the well-being of others (Althof and Berkowitz, 2006; Sherrod and Lauckhardt, 2009).

More recently, this approach has somehow been advocated by Bo Rothstein (2018) as a way of fighting systemic corruption. His suggestion that successful examples of modern citizenship resulted from establishing universal access to public education follows an earlier argument regarding 'generalized trust' and its correlation with low levels of corruption (Rothstein, 2011). Briefly described, his 'indirect' approach recognizes that the degree of universalism of public agenciesin particular, their impartiality — has a decisive impact on the transition from patrimonial forms of organization to those characterized by a high quality of government and low levels of corruption (Rothstein, 2005). That impact is explained by the level of social trust which it fosters, which in turn helps solve the collective action problem causing a corrupt equilibrium (Persson et al., 2013).

The significance of citizenship development for controlling secondary corruption is further suggested by the earlier argument regarding the expression of political agency through individual rights. It is the nature and range of specific rights which inform the labeling of behaviors as either corrupt or not corrupt, a matter which is evident in the literature. Friedrich $(2002,21)$ points out that the sale of government posts under absolute monarchies could not be considered corruption, for leaders enjoyed a socially recognized control over those resources. However, by considering the fact that rights are themselves divided (both analytically and in their historical evolution) between civil, political, and social rights (Mann, 1987; Turner, 1990), the argument may be pushed beyond a recognition of general association, making it possible to interpret the geographical and temporal application of the label 'corruption' by reference to specific and properly-internalized rights: political rights creating intolerance of political abuse, and social rights resulting in the condemnation 
of profiteering.

\section{Conclusions}

In the past, the explicit identification of 'private gain' as a constitutive element of corruption gave track to its interpretation as a phenomenon applying exclusively to 'public' affairs, building from the significance that the division between public and private spheres has played in the development of the modern state. However, the meaning of corruption understood as 'the abuse of entrusted power for private gain' makes it a relational concept centered around role expectations-a fact which is evident in its applicability across the three basic levels of human organization: public sector, private sector, and private sphere. Thus, it would be correct to say that the concept of corruption explored here applies beyond its constrictive use in governmental discourse and reaches the level of moral judgement across all spheres of human action.

Corruption is a behavior framed by the relationship between individuals and the group to which they belong, and it arises precisely from the gap between actions and expectations. The argument presented here proposed to build on this well-known feature and to interpret corruption based on a historical exploration of the nature of power transferred from the individual to the group, and of the moral norms and social conventions dictating the powers which ought to be entrusted rather than transacted. In doing so, it explored the possibility of recognizing corruption as a deviant behavior throughout different eras by reference to the evolution of individual political identity (from band member to subject to citizen) and the increasing duties of political authority (from ceremonial duties to public accountability). Such an interpretation continues an emerging agreement among scholars regarding the role of a broadening public sphere (brought about by the centralization of power by modern states) in giving rise to our modern concern with corruption. However, it goes further by suggesting that efforts to control public and private corruption may both be natural results of the specific ways in which individual agency has evolved over the past two centuries, and the consequent reinterpretation of power from a rewarded good to a form of fiduciary trust. 
From the conclusions that were logically drawn, a number of research avenues present themselves for further exploration of the real consequences of understanding corruption in the way presented here. Crucially to the next stage, the cognitive and social elements that make up the related concepts of entrusted and rewarded power must be clarified to provide empirical support to the interpretation of corruption in those terms. The relation between political agency and power transfer also requires further analysis, considering specific conditions of civil, political, and social rights, and how these relate to an individual's locus of control and self-efficacy. Finally, more work must be done to unpack the concepts of primary and secondary corruption to confirm their applicability beyond analytical constructs, and to identify the exact functional range of their applicability. Once the moral weight of specific forms of corrupt behavior has been addressed, a cognitive model for individual decision-making may be explored to evaluate the potential of different styles of ethics management in organizations. By taking the first step in the quest for a unified theory of corruption, this study represents the basis for new and exciting inquiries which may someday provide a definitive answer regarding the innermost workings of corruption.

\section{References}

Althof, W. and Berkowitz, M. W. (2006). Moral education and character education: Their relationship and roles in citizenship education. Journal of moral education, 35(4):495-518.

Anderson, M. (1984). The evolution of eusociality. Annual Review of Ecology and Systematics, 15(1):165-189.

Aquino, K., Freeman, D., Reed, I., Lim, V. K., and Felps, W. (2009). Testing a social-cognitive model of moral behavior: the interactive influence of situations and moral identity centrality. Journal of personality and social psychology, 97(1):123.

Arjoon, S. (2006). Striking a balance between rules and principles-based approaches for effective governance: A risks-based approach. Journal of Business Ethics, 68(1):53-82. 
Abuse of Entrusted Power for Private Gain

Becker, H. S. (1963). Outsiders: A Study in the sociology of deviance. New York: Free Press.

Berkowitz, M. W. (2000). Civics and moral education. In Moon, B., B. S. and Ben-Peretz, M., editors, Routledge international companion to education, pages 897-909. New York: Routledge.

Chudek, M. and Henrich, J. (2011). Culture-gene coevolution, norm-psychology and the emergence of human prosociality. Trends in cognitive sciences, 15(5):218-226.

Crone, P. (1993). The tribe and the state,. In Hall, J. A., editor, The State: Critical Concepts, pages 446-73. Oxford: Blackwell.

De Graaf, G. (2007). Causes of corruption: Towards a contextual theory of corruption. Public Administration Quarterly, 31(1-2):39-86.

Denhardt, K. G. (1994). Organizational structure as a context for administrative ethics. In Cooper, T. L., editor, Handbook of Administrative Ethics, pages 169-82. New York: Marcel Dekker.

Easton, D. (1965). A systems analysis of political life. Chicago: The University of Chicago Press.

French, J., Raven, B., and Cartwright, D. (1959). The bases of social power. Classics of organization theory, 7:311-320.

Fried, M. H. (1967). The evolution of political society: An essay in political anthropology, volume 7. New York: Random House.

Friedrich, C. J. (2002). Corruption concepts in historical perspective. In Heidenheimer, A. J. and Johnston, M., editors, Political Corruption: Concepts Contexts, pages 15-23. New Brunswick: Transaction Publishers.

Fukuyama, F. (2011). The origins of political order: From prehuman times to the French Revolution. London: Profile Books Ltd.

Gabel, J. T., Mansfield, N. R., and Houghton, S. M. (2009). Letter vs. spirit: The evolution of compliance into ethics. American Business Law Journal, 46(3):453-486. 
Gardiner, J. (2002). Defining corruption. In Heidenheimer, A. J. and Johnston, M., editors, Political corruption: Concepts and contexts, pages 25-40. New Brunswick: Transaction Publishers.

Giddens, A. (1984). The constitution of society: Outline of the structuration theory. Cambridge: Polity Press.

Goldhamer, H. and Shils, E. A. (1939). Types of power and status. American journal of Sociology, 45(2):171-182.

Heidenheimer, A. J. (2002). Perspectives on the perception of corruption. In Heidenheimer, A. J. and Johnston, M., editors, Political corruption: Concepts and contexts, pages 141-154. New Brunswick: Transaction Publishers.

Huntington, S. P. (1968). Political order in changing societies. New Haven: Yale University Press.

Jancsics, D. (2019). Corruption as resource transfer: An interdisciplinary synthesis. Public Administration Review, https://doi.org/10.1111/puar.13024.

Johnston, M. (2014). Corruption, contention and reform: the power of deep democratization. New York: Cambridge University Press.

Johnston, M. (2018). Reforming reform: Revising the anticorruption playbook. Daedalus, 147(3):50-62.

Karklins, R. (2005). The System Made Me Do it: Corruption in Post-communist Societies. New York: M.E. Sharpe.

Kohlberg, L. and Hersh, R. H. (1977). Moral development: A review of the theory. Theory into practice, $16(2): 53-59$.

Leff, N. H. (1964). Economic development through bureaucratic corruption. American behavioral scientist, 8(3):8-14.

Lewis, C. W. and Gilman, S. C. (2005). The ethics challenge in public service: A problem-solving guide. San Francisco: Jossey-Bass, 2nd edition. 
Lukes, S. (2005). Power: A Radical View. New York: Palgrave Macmillan, 2nd edition.

Maesschalck, J. (2004). Approaches to ethics management in the public sector: A proposed extension of the compliance-integrity continuum. Public Integrity, 7(1):20-41.

Mann, M. (1987). Ruling class strategies and citizenship. sociology, 21(3):339-354.

McMullan, M. (1961). A theory of corruption. The Sociological Review, 9(2):181-201.

Moore, C. (2008). Moral disengagement in processes of organizational corruption. Journal of Business Ethics, 80(1):129-139.

Nisbet, R. (1974). Citizenship: two traditions. Social Research, 41(4):612-637.

Noonan, J. T. (1984). Bribes: The intellectual history of a moral idea. New York: Macmillan.

Nye, J. S. (1967). Corruption and political development: A cost-benefit analysis. American political science review, 61(2):417-427.

Persson, A., Rothstein, B., and Teorell, J. (2013). Why anticorruption reforms failsystemic corruption as a collective action problem. Governance, 26(3):449-471.

Philp, M. (2017). Conceptualizing political corruption. In Heidenheimer, A. J. and Johnston, M., editors, Political Corruption: Concepts Contexts, pages 25-40. New Brunswick: Transaction Publishers.

Pozsgai Alvarez, J. (2015). Low-level corruption tolerance: An action-based approach for peru and latin america. Journal of Politics in Latin America, 7(2):99-129.

Rayner, J., Williams, H. M., Lawton, A., and Allinson, C. W. (2010). Public service ethos: Developing a generic measure. Journal of Public Administration Research and Theory, 21(1):27-51.

Reisman, W. M. (1979). Folded lies: Bribery, crusades, and reforms. New York: Free Press.

Reynolds, S. J. (2006). Moral awareness and ethical predispositions: investigating the role of individual differences in the recognition of moral issues. Journal of Applied Psychology, 91(1):233. 
Rose-Ackerman, S. (2018). Corruption \& purity. Daedalus, 147(3):98-110.

Rotaru, C., Bodislav, D.-A., and Georgescu, R. A review of corruption based on the social and economic evolution of ancient greece and ancient rome. Theoretical \& Applied Economics, 23(2):239-248.

Rothstein, B. (2005). Social traps and the problem of trust. New York: Cambridge University Press.

Rothstein, B. (2011). The quality of government: Corruption, social trust, and inequality in international perspective. Chicago: University of Chicago Press.

Rothstein, B. (2018). Fighting systemic corruption: The indirect strategy. Daedalus, 147(3):35-49.

Schuman, H. (1972). Attitudes vs. actions versus attitudes vs. attitudes. Public Opinion Quarterly, 36(3):347-354.

Scott, J. C. (1972). Comparative political corruption. New Jersey: Prentice Hall.

Sherrod, L. R., Flanagan, C., and Youniss, J. (2002). Dimensions of citizenship and opportunities for youth development: The what, why, when, where, and who of citizenship development. Applied Developmental Science, 6(4):264-272.

Sherrod, L. R. and Lauckhardt, J. (2009). The development of citizenship. In Lerner, R. M. and Steinberg, L., editors, Handbook of Adolescent Psychology, Volume 2: Contextual Influences on Adolescent Development, pages 372-407. New Jersey: John Wiley \& Sons.

Shupak, N. (1992). A new source for the study of the judiciary and law of ancient egypt:" the tale of the eloquent peasant". Journal of Near Eastern Studies, 51(1):1-18.

Swart, K. W. (2012). Sale of offices in the seventeenth century. Springer.

Torsello, D. and Venard, B. (2016). The anthropology of corruption. Journal of Management Inquiry, 25(1):34-54. 
Turner, B. S. (1990). Outline of a theory of citizenship. Sociology, 24(2):189-217.

Yoffee, N. and Norman, Y. (2005). Myths of the archaic state: Evolution of the earliest cities, states, and civilizations. New York: Cambridge University Press. 